\title{
A study on stratified air conditioning cooling load calculation model for a large space building
}

\author{
Ning Cai ${ }^{*}$, Dongliang Zhang ${ }^{1}$, Chen Huang ${ }^{2}$ \\ ${ }^{1}$ College of Energy and Power Engineering, Nanjing Institute of Technology, Nanjing 211167, China \\ ${ }^{2}$ School of Environment and Architecture, University of Science and Technology, Shanghai 200093, China
}

Corresponding Author Email: caining@njit.edu.cn

https://doi.org/10.18280/ijht.360210

Received: 9 October 2017

Accepted: 17 February 2018

\section{Keywords:}

calculation model, stratified air conditioning, cooling load, large space building

\begin{abstract}
Based on the theory of regional heat and mass balance, a stratified air-conditioning load calculation model suitable for large-space buildings was established. A test of a large-space building under summer conditions was conducted to verify the calculation results of indoor vertical temperature distribution. The stratified air-conditioning cooling load calculated by the model was compared with the actual air-conditioning cooling capacity. The calculation results showed that the difference between the actual air-conditioning cooling load and the model calculation result was $14 \%$. Based on the model, the vertical temperature distribution under variable operating conditions was predicted.
\end{abstract}

\section{INTRODUCTION}

Summer air-conditioning cooling load is important for the design of air-conditioning systems. For large-space buildings, the structural characteristics and air flow organization are different from ordinary public buildings. Because the density of hot air is small, the upper zone temperature is very high. The personnel activity space is located in the area below 2 meters. From the perspective of energy conservation, effective air stratification is often achieved through the air distribution of stratified air conditioners. Therefore, when calculating the cooling load, the temperature of the entire space cannot be considered as a single point temperature. The vertical temperature stratification of the air and the inner surface of the envelope should be considered, as well as the convective heat transfer and radiative heat transfer of the upper non-airconditioned zone to the lower air-conditioned zone.

At present, theoretical calculations or computer simulations were often used in the study of stratified air-conditioning load calculation for large space buildings. In theoretical research, the whole-house cooling load calculation method of ordinary buildings was often used. In this method, the design temperature of the lower air-conditioning zone is considered as a single point temperature, the hourly cooling load calculation was adopted in design of air condition system. The empirical equation was used to calculate air and wall temperature in the upper non-air-conditioned zone. The convective and radiative transfer heat from non-airconditioned zone to air-conditioning zone were calculated as an additional cooling load in the lower air-conditioning zone [1-3] This method has been widely used for calculating the cooling load of large space buildings. Kang Zhao [4] proposed a new method to calculated the cooling capacity of a radiant floor in the large spaces of an airport,

In addition, the theoretical research on stratified airconditioning load in the lower air supply distribution were focused on the stratified height [5], the load efficiency coefficient [6], the lower air supply load correction factor [7], the supply and return air heights, the indoor heat source distribution [8] and outdoor disturbances affect the stratified load.

Through computer simulation to study the stratified airconditioning load, a single-point or two-point model can be used to establish the regional heat and mass balance equation [9-10]. The indoor vertical or horizontal temperature distribution can be calculated by the model [11-12]. It also can be used to analyze the influencing factors of load, such as supply and return air, enclosure structure, and heat source and so on. The variation law of specific building cooling load of stratified air-condition system under different influencing factors were studied. Then the method of general airconditioning cooling load calculation can be concluded. Yuanlin $\mathrm{Yu}$ [13] proposed a new inflow turbulence generation method for LES and the new NSRFG technique was then applied to the numerical simulation of the turbulent flow around a CAARC standard building model. Yong Wan [14] calculated the theoretical load index by solving the model for inner sur-face temperature of the building envelope based on the modified radiant heat transfer method, put forward a recommendation for usage of the stratified air conditioning design.

With the development of computer technology, theoretical and experimental research was a powerful complement. Such methods are widely used in various types of large space buildings. However, in single-point or two-point model modeling, the indoor area was often simply divided into an upper non-air-conditioned area and a lower air-conditioned area. The vertical temperature distribution at different indoor heights was not taken into consideration. Therefore, the airconditioning cooling load calculated by the single-point or two-point model has some limitations.

This paper established a stratified air-conditioning load calculation model suitable for large-space buildings through the regional heat-mass balance equation. The indoor space was divided into multiple regions in the vertical direction (8 regions), taking full account of the indoor air temperature. The distribution in the vertical direction was verified and analyzed using the test results of the air-conditioning cooling load in the 
summer conditions. The feasibility and accuracy were discussed, providing the ideas and directions for the airconditioning cooling load calculation of large space buildings.

\section{ESTABLISHMENT OF STRATIFIED AIR CONDITIONING LOAD CALCULATION MODEL}

The stratified air-conditioning load calculation model was based on the regional heat and mass balance equation [11], and on this basis, it was expanded and revised. The basic idea of the regional thermal model was to divide a single indoor space into a limited large-scale area. It is considered that the air in the area is completely uniform, the relevant parameters (such as temperature, concentration, etc.) were equal, and there was an exchange of heat and mass between the areas, and the quality was established. The energy balance equation was used to study the temperature distribution and flow conditions in the space. Compared with the single node energy consumption, ventilation, and airflow prediction models, it can provide more abundant information and can obtain the distribution parameter solutions in a certain scale.
In this paper, the large space building was divided into several isothermal areas in the vertical direction. A heat and mass balance model was established for each area. The heat exchange equation was established for the body flow air regions and the wall flow heat and mass exchange. The basic composition of the stratified air-conditioning load calculation model for indoor air temperature and wall temperature was shown in Fig.1, where $t_{(i)}$ was the i-th of air temperature layer, $t_{b(i, K)}$ was wall surface temperature of enclosure structure, $\mathrm{K}$ was the number of the four enclosures, $t_{(\mathrm{c})}$ and $t_{(\mathrm{f})}$ were roof temperature and floor temperature,; $m_{c(i+1)}$ was $i+1$-th body flow air inflow $i$-th of mass flow; $m_{\text {out }(i, K)}$ and $m_{\text {in }(i, K)}$ were quality exchange between wall flow and body flow in each layer; $m_{d(i, K)}$ was mass exchange between wall flows in each layer; $t_{m(i, K)}$ was the average temperature of the wall flow; $m_{s(i)}$ and $m_{h(i)}$ were air-conditioning air supply and return air volume of each floor; $m_{j(i)}$ was blowing of the jet at each layer; $q_{(i-(i-1))}$ was heat exchange due to temperature difference between body flow $i$-th layer and $i$-1-th layer; $q_{w(i, K)}$ were heat introduced into the inner wall surface through the enclosure structure outdoors.

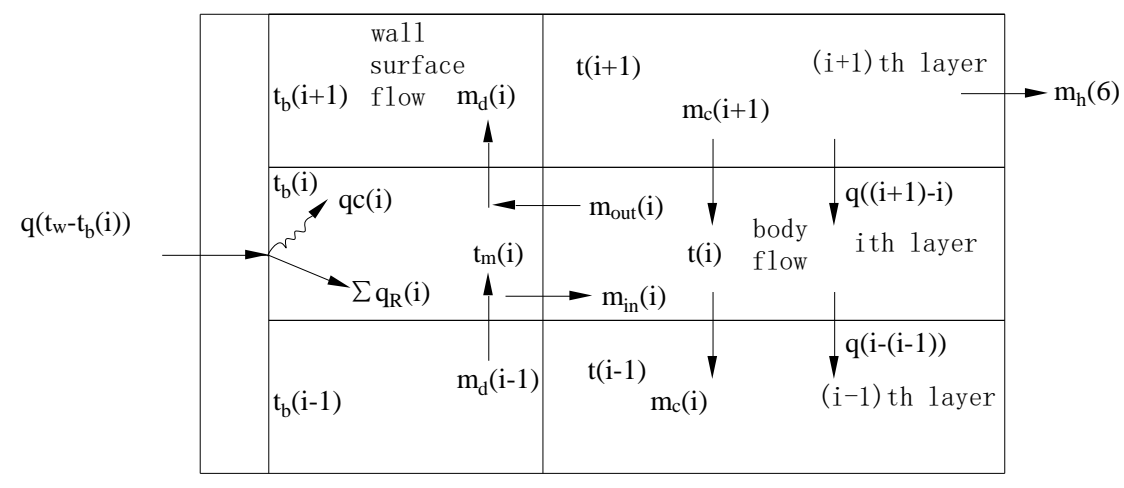

Figure 1. Composition of the stratified air-conditioning load calculation model

According to the analysis of the wall flow characteristics, $m_{\text {in }(i, K)}, m_{\text {out }(i, K)}$, and $m_{d(i, K)}, m_{c(i)}$ of each layer can be known according to Table 1 . As an intermediate amount between each layer, the wall flow and the main flow can be solved at the same time. The relationship between various intermediate parameters and the wall surface flow average temperature were given in Equation (1) and (2). The relationship between the convection heat transfer and the temperature difference heat exchange in each layer of the body flow area was given in Equation (3) and (4). The radiation, and convection heat transfer were combined at the inner wall of the envelope structure. The principle of energy conservation can be used to list the energy balance equations for the surface $i$, as shown in equation (5). $q_{d(i)}$ was the convection heat transfer between the $i$-surface and the indoor air (Equation 6). $q_{R(i)}$ was the radiative heat exchange between the $i$-surface and the indoor surface (Equation 7). The angle coefficient $F_{i j}$ was calculated by the Monte Carlo method. $q_{\lambda(i)}$ was the heat exchange from outdoor air to inner wall surface (Equation 8). Equation (9) was the radiative heat transfer equation of each wall. Equation (10) was the heat-mass exchange equation of the body flow air. Equation (11) was the final matrix equation of the model. Through iterative solution, the air temperature and the inside of wall temperature can be calculated. The coupling calculation of wall temperature and indoor air temperature
(Equation 10) was considered in the model. Monte Carlo calculation was also conducted for the angle coefficient.

$$
\begin{aligned}
& m_{m(i, K)}=m_{d(i-1, K)}+m_{\text {out }(i, K)} \\
& t_{m(i, K)}=\left[m_{d(i-1, K)} \cdot t_{m(i-1, K)}+m_{\text {out }(i, K)} \cdot t_{d(i, K)}\right] / m_{m(i, K)} \\
& q_{c}(i)=c_{p} m_{c(I+1)}\left[t_{(I+1)}-t_{(I)}\right]+c_{p} m_{c(I)}\left[t_{(I-1)}-t_{(I)}\right] \\
& q_{c o n d}(I)=C_{B} A_{B(I+1)}\left[t_{(I+1)}-t_{(I)}\right]+C_{B} A_{B(I)}\left[t_{(I-1)}-t_{(I)}\right] \\
& q_{d(i)}+q_{R(i)}+q_{\lambda(i)}=0 \\
& q_{d(i)}=\alpha_{d(i)} \cdot\left(t_{(i)}-t_{b(i, K)}\right) \\
& q_{R(i)}=-\varepsilon_{i} \cdot \sigma \cdot \sum_{j=1}^{N} F_{i j} \cdot\left(t_{b(i, K)}^{4}-t_{b(j, K)}^{4}\right)
\end{aligned}
$$


$q_{\lambda(i)}=\frac{1}{\frac{1}{K_{(i)}}-\frac{1}{\alpha_{d(i)}}} \cdot\left(T_{Z}-t_{b(i, K)}\right)$

$=\alpha_{w}^{\prime} \cdot\left(T_{Z}-t_{b(i, K)}\right)$

$\alpha_{d} \cdot t_{(i)}-\left(\alpha_{d}+4 T_{b m}^{3} \cdot \varepsilon_{i} \cdot \sigma \cdot\left(\sum_{j=1}^{i-1} F_{l j}+\sum_{j=i+1}^{N} F_{i j}+F_{i f}\right.\right.$

$\left.\left.+F_{i C}+\alpha_{W}\right)\right) \cdot t_{b(i, K)}+4 T_{b m}^{3} \cdot \varepsilon_{i} \cdot \sigma \cdot\left(\sum_{j=1}^{i-1}\left(F_{i j} \cdot t_{b(j, K)}\right)\right.$

$\left.+\sum_{j=i+1}^{N}\left(F_{i j} \cdot T_{b(j, K)}\right)+F_{i f} \cdot T_{(f)}+F_{i C} \cdot T_{(c)}\right)+\alpha_{W} \cdot t_{a}=0$

$0=\sum_{K=1}^{m} C \cdot m_{i n(i, K)} \cdot\left[t_{m(i, K)}-t_{(i)}\right]-$

$\sum_{K=1}^{m} C \cdot m_{\text {out }(i, K)} \cdot\left[t_{(i)}-t_{b m(i)}\right]$

$+C_{B(i)} \cdot A_{B(i)} \cdot\left[t_{(i-1)}-t_{(i)}\right]+C_{B(i+1)} \cdot A_{B(i)} \cdot\left[t_{(i+1)}-t_{(i)}\right]$

$+C \cdot m_{c(i+1)} \cdot\left[t_{(i+1)}-t_{(i)}\right]-C \cdot m_{c(i)} \cdot\left[t_{(i-1)}-t_{(i)}\right]$

$+C \cdot m_{S}^{\prime} \cdot\left[t_{S}^{\prime}-t_{j(i)}\right]$

$\left[\begin{array}{cccccccc}A_{11} & A_{12} & \cdots & A_{1 N} & B_{11} & B_{12} & \cdots & B_{1 N} \\ A_{21} & A_{22} & \cdots & A_{2 N} & B_{21} & B_{22} & \cdots & B_{2 N} \\ & & \vdots & & & & \vdots & \\ A_{N 1} & A_{N 2} & \cdots & A_{N N} & B_{N 1} & B_{N 2} & \cdots & B_{N N} \\ \alpha_{d} & 0 & \cdots & 0 & C_{11} & C_{12} & \cdots & C_{1 N} \\ 0 & \alpha_{d} & \cdots & 0 & C_{21} & C_{21} & \cdots & C_{2 N} \\ & & \vdots & & & & \vdots & \\ 0 & \cdots & 0 & \alpha_{d} & C_{N 1} & C_{N 2} & \cdots & C_{N N}\end{array}\right] \times\left[\begin{array}{c}t_{(1)} \\ t_{(2)} \\ \vdots \\ t_{(N)} \\ t_{b(1)} \\ t_{b(2)} \\ \vdots \\ t_{b(N)}\end{array}\right]=\left[\begin{array}{c}D_{1} \\ D_{2} \\ \vdots \\ D_{N} \\ E_{1} \\ E_{2} \\ \vdots \\ E_{N}\end{array}\right]$

The convective heat transfer coefficient of the inner surface depends on the material of each wall and the flow pattern of the air flow. In the model, the heat transfer coefficient between the solid wall and the air adopts a function of the temperature difference index calculation method. For the natural convection and forced convection, the coefficients were corrected. The equation for calculating the convective heat transfer coefficient was shown in equation (12), where the correction coefficient $\mathrm{A}_{\mathrm{C} 0}$ and the index $\mathrm{B}_{\mathrm{C} 0}$ were selected according to the surface characteristics of the building envelope.

$\alpha_{d i}=A_{C 0} \times\left(t_{b(i, K)}-t_{(I)}\right)^{B_{C 0}}$

Analysis of the summer cooling load of large space buildings shows that the formation of cooling load was mainly caused by the convection heat exchange between the inner wall surface of the envelope structure and the indoor air. The temperature rise of the inner wall surface of the envelope structure mainly consists of two parts: heat transfer of enclosure structure and radiation heat transfer of inner wall. In the ideal steady state, the temperature of the inner wall surface was a combination of radiative heat transfer and convection heat transfer. The influence of radiation heat transfer was taken into account. Therefore, the summer cooling load of the stratified air conditioner can be calculated by equation (13) which included the convective heat transfer of floor, ceiling, inner wall surface, the corresponding air layer. This equation was a steady-state load calculation equation, which can be used as a steady-state summer cooling load calculation method under an outdoor weather parameter or under the most unfavorable conditions. In the subsequent study, an unsteady solution model can be established to consider the envelope, structural heat storage, indoor personnel interference, etc.

$$
\begin{aligned}
& q_{c l}=\alpha_{f} A_{f}\left[t_{f}-t_{(1)}\right]+ \\
& \alpha_{c} A_{c}\left[t_{c}-t_{(n)}\right]+\sum_{i=1}^{n} \alpha_{d(i, K)} A_{i}\left[t_{b(i, k)}-t_{(i)}\right]
\end{aligned}
$$

In the equation, $\alpha_{f}$ was the convection heat transfer coefficient of the floor and the first layer of air, $\mathrm{W} / \mathrm{m}^{2}{ }^{\circ} \mathrm{C} ; A_{f}$ was floor area, $\mathrm{m}^{2} ; t_{f}$ was the floor temperature, ${ }^{\circ} \mathrm{C} ; t_{(1)}$ was the first layer of air temperature, ${ }^{\circ} \mathrm{C} ; \alpha_{c}$ was the roof and $\mathrm{n}$-th layer air convection heat transfer coefficient, $\mathrm{W} / \mathrm{m}^{2}{ }^{\circ} \mathrm{C} ; A_{c}$ was the ceiling area, $\mathrm{m}^{2} ; t_{c}$ was the ceiling temperature, ${ }^{\circ} \mathrm{C} ; t(n)$ was the n-th layer air temperature, ${ }^{\circ} \mathrm{C} ; \alpha_{d(i, K)}$ was the i-th layer inner wall surface and the $\mathrm{i}$-th layer The convection heat transfer coefficient of air, $\mathrm{W} / \mathrm{m}^{2 \circ} \mathrm{C} ; A_{i}$ was the area of the inner wall surface of the i-th layer, $\mathrm{m}^{2} ; t_{b(i, K)}$ was the inner wall surface temperature of the $\mathrm{i}$-th layer, ${ }^{\circ} \mathrm{C} ; t(i)$ was the $\mathrm{i}$-th layer air temperature, ${ }^{\circ} \mathrm{C}$.

\section{EXPERIMENTAL TEST PROGRAM AND ANALYSIS}

\subsection{Experimental test program}

Experimental tests of summer cooling conditions were conducted at a large space experiment base. The experimental base was $20 \mathrm{~m}$ long and $14.8 \mathrm{~m}$ wide. The lowest point of the slope roof was $6 \mathrm{~m}$ and the highest point was $8.75 \mathrm{~m}$. The modular air-cooled heat pump chiller/cooler unit was used as the cold source and the cooling capacity was $67 \mathrm{~kW}$. The airconditioning box was a return air system with a rated air volume of $20000 \mathrm{~m}^{3} / \mathrm{h}$. The fan adopts a frequency converter to adjust the air volume. During the experimental test, the fresh air inlet was closed. Nozzle outlet air supply was adopted as the air distribution of the stratified air conditioner. The layout of the nozzles was shown in Fig. 2.

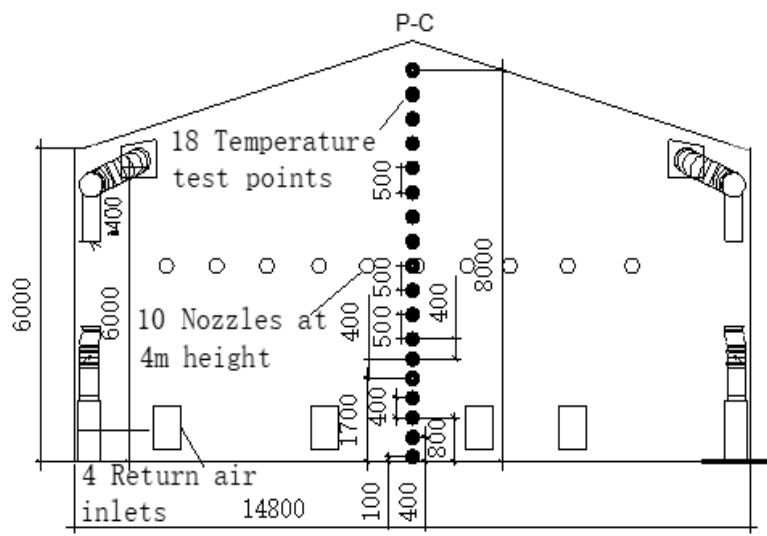

Figure 2. Nozzle position and measuring point layout 
At the $4 \mathrm{~m}$ vertical height of the western Wall, 10 nozzles are arranged with a diameter of $174 \mathrm{~mm} .4$ air outlets with the size of $600 \mathrm{~mm} \times 900 \mathrm{~mm}$ are located below the nozzles. According to the characteristics of the airflow organization formed by jets, a vertical temperature line (PC) was arranged in the center of the room. One measuring point was arranged at $0.1 \mathrm{~m}$ from the ground. The measuring points were arranged every $0.4 \mathrm{~m}$ below $2.5 \mathrm{~m}$. When vertical height was larger than $2.5 \mathrm{~m}$, the regional measuring point interval was $0.5 \mathrm{~m}$.

Experimental test instruments are shown in Table 1.

Table 1. Test instruments

\begin{tabular}{c|c|c}
\hline Test Parameters & Test Instrument & Model \\
\hline Outdoor solar radiation intensity & Solar radiometer & SWP-LCD-R8101-80-18 \\
Indoor temperature & thermocouple & HUMLOG 10 (T) \\
Supply Humidity & Humidity Recorder & testo174 \\
Supply air temperature & Testo temperature & Thermcamp P20 \\
Enclosure Inner Surface Temperature & Infrared Camera & H103T.0 \\
Indoor wind speed & universal anemometer & HD2003 \\
Outdoor parameters & Outdoor weather station &
\end{tabular}

\subsection{Analysis of test results}

During the experiment, the supply air volume was set to $7600 \mathrm{~m}^{3} / \mathrm{h}$. In order to obtain the actual cooling capacity of the air-conditioning system under stable conditions, the supply air temperature, and air temperature at the height of $1.7 \mathrm{~m}$ on the PC line were shown in Fig.3. The trend of wind temperature changing with time can be seen from the figure. The temperature at the height of $1.7 \mathrm{~m}$ in the room and the return air temperature were basically the same and became stable after 11:30. The data after this time can be used in the model. According to the supply and return air temperature difference and the supply air volume, the air-conditioning cooling capacity at each time can be calculated, as shown in Fig. 3. The quadratic polynomial of the cooling capacity change over time was also given. In order to facilitate the comparison of subsequent model calculation results, the data at 12:00 are taken as the basis for calculation and comparison. The parameters are listed in Table 2.

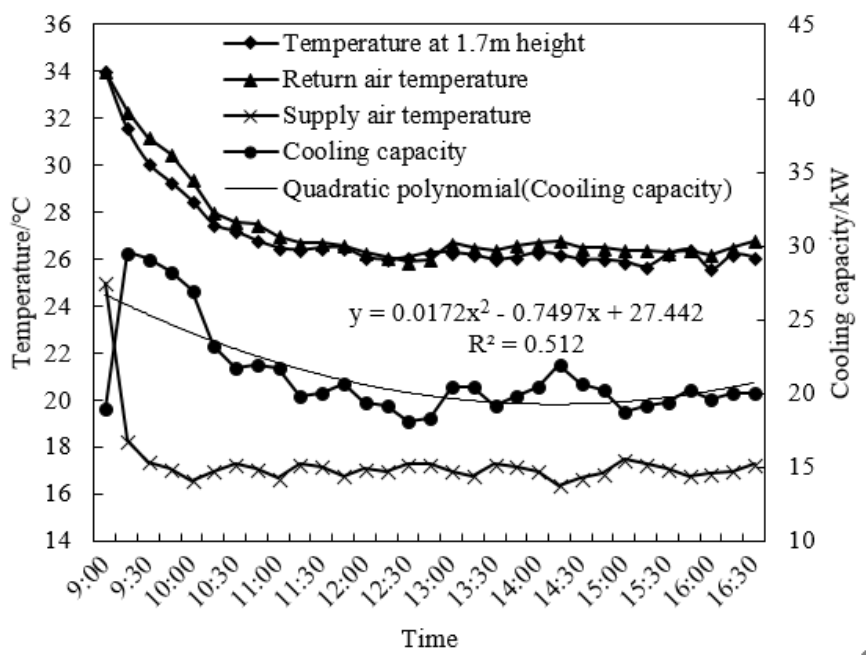

Figure 3. Curve of each parameter with time in experimental test

Table 2. Test result of various parameters at 12:00

\begin{tabular}{ccccccccc}
\hline $\begin{array}{c}\text { Outside } \\
\text { temperature } \\
/{ }^{\circ} \mathrm{C}\end{array}$ & $\begin{array}{c}\text { Horizontal } \\
\text { solar } \\
\text { radiation } / \\
\mathrm{W} / \mathrm{m}^{2}\end{array}$ & $\begin{array}{c}\text { Vertical } \\
\text { solar } \\
\text { radiation } / \\
\mathrm{W} / \mathrm{m}^{2}\end{array}$ & $\begin{array}{c}\text { Supply air } \\
\text { temperature } \\
/{ }^{\circ} \mathrm{C}\end{array}$ & $\begin{array}{c}\text { Supply } \\
\text { air } \\
\text { volume } / \\
\mathrm{m}^{3} / \mathrm{h}\end{array}$ & $\begin{array}{c}\text { Return air } \\
\text { temperature } \\
/{ }^{\circ} \mathrm{C}\end{array}$ & $\begin{array}{c}\text { Floor } \\
\text { temperature } \\
/{ }^{\circ} \mathrm{C}\end{array}$ & $\begin{array}{c}\text { Roof } \\
\text { temperature } \\
/{ }^{\circ} \mathrm{C}\end{array}$ & $\begin{array}{c}\text { conditioning } \\
\text { cooling } \\
\text { capacity } / \mathrm{W}\end{array}$ \\
\hline 35 & 445 & 300 & 17.1 & 7600 & 26.3 & 30.3 & 36.6 \\
\hline
\end{tabular}

\section{MODEL CALCULATION RESULTS AND ANALYSIS}

Table 3. Model structure input data

\begin{tabular}{cccccc}
\hline $\begin{array}{c}\text { Number } \\
\text { of } \\
\text { Zones }\end{array}$ & $\begin{array}{c}\text { Layer } \\
\text { Supply } \\
\text { Zone } \\
\text { Layer }\end{array}$ & $\begin{array}{c}\text { Return } \\
\text { Zone/Layer }\end{array}$ & $\begin{array}{c}\text { Sidewall } \\
\text { Area / } \\
\mathrm{m}^{2}\end{array}$ & $\begin{array}{c}\text { Roof } \\
\text { Area/ } \\
\mathrm{m}^{2}\end{array}$ & $\begin{array}{c}\text { Floor } \\
\text { Area / } \\
\mathrm{m}^{2}\end{array}$ \\
\hline 8 & 5 & 1 & 109 & 316 & 296 \\
\hline
\end{tabular}

Table 4. Calculation equation of surface heat transfer coefficient

\begin{tabular}{cccc}
\hline $\begin{array}{c}\text { External } \\
\text { protective } \\
\text { structure }\end{array}$ & $\begin{array}{c}\text { Roofing } \\
\text { Natural } \\
\text { Convection } \\
/ \mathrm{W} / \mathrm{m}^{2 \circ} \mathrm{C}\end{array}$ & $\begin{array}{c}\text { Wall } \\
\text { Natural } \\
\text { Convection } \\
/ \mathrm{W} / \mathrm{m}^{2 \circ} \mathrm{C}\end{array}$ & $\begin{array}{c}\text { Surface } \\
\text { Forced } \\
\text { Convection } / \mathrm{W} / \mathrm{m}^{2 \circ} \mathrm{C}\end{array}$ \\
\hline$A_{\mathrm{C} 0}$ & 3.0 & 1.5 & 3.0 \\
$B_{\mathrm{C} 0}$ & 0.0 & $1 / 3$ & 0.0 \\
\hline
\end{tabular}

According to the calculation needs of the model, the actual test building was divided into eight layers in the height direction. The structural parameters were shown in Table 3. The correction factors in the calculation equation were shown in Table 4. These correction factors were used for calculating heat transfer coefficient of the envelope structure. The air temperature, wall temperature, convective heat transfer coefficient of each layer under the stable working conditions in the experimental building can be calculated by the model above. The cooling load can be calculated by Equation 13 .

\subsection{Analysis of indoor vertical temperature distribution and cooling load calculation results}

The comparison between the calculated values and the experimental values of the inner wall surface temperature and the indoor vertical temperature distribution under experimental conditions was shown in Fig. 4. It can be seen that, the nozzles were located at a height of $4 \mathrm{~m}$ (fifth level), 
because of the suction effect, there was an obvious sub-level in the indoor vertical height of about $5 \mathrm{~m}$. Above the sub-level was non-air-conditioned area and below was the airconditioned area. The vertical temperature distribution in the air-conditioned area was relatively uniform. Due to the impact of the floor heat transfer, there was a small temperature gradient near the ground. It can meet the requirements of the thermal comfort of the human body $(0.1 \mathrm{~m}$ and $1.1 \mathrm{~m}$ temperature difference was less than $3{ }^{\circ} \mathrm{C}$ ). It can be seen that the calculated values and experimental values of indoor vertical temperature distribution and wall temperature distribution agreed well with each other. The maximum relative error between the calculated and measured values of air temperature was $13.5 \%$, and the maximum relative error of internal wall surface temperature was $17 \%$. The calculated data was used for subsequent cooling load calculation analysis.

From the results of the vertical temperature distribution calculation, it can be seen that the multi-area thermal mass balance model calculation result was closer to the actual situation and was in good agreement with the experimental result.

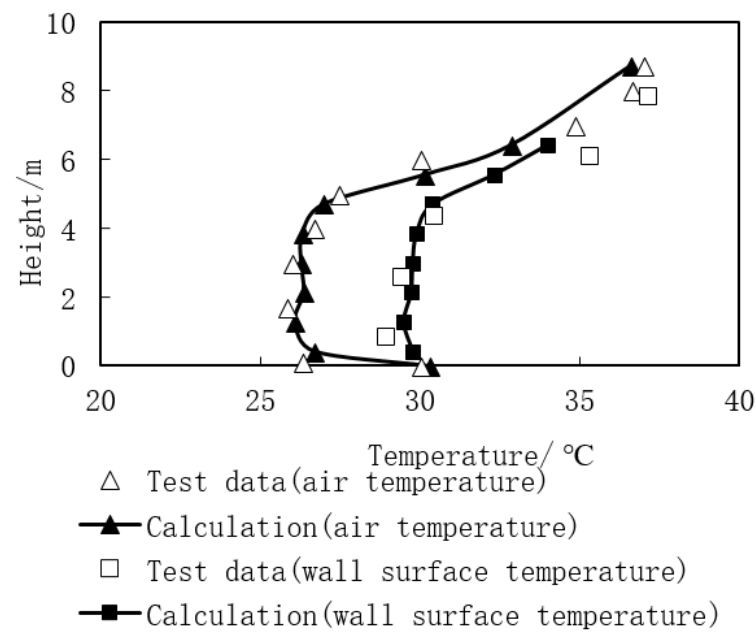

Figure 4. Experimental verification of indoor vertical temperature distribution and wall temperature

Table 5. Calculation results of cooling load at each floor

\begin{tabular}{|c|c|c|c|c|c|}
\hline $\begin{array}{c}\text { Model } \\
\text { stratification }\end{array}$ & $\begin{array}{l}\text { Air temperature of } \\
\text { each layer } /{ }^{\circ} \mathrm{C}\end{array}$ & $\begin{array}{l}\text { Wall surface temperature } \\
\text { of each layer } /{ }^{\circ} \mathrm{C}\end{array}$ & $\begin{array}{c}\text { Convection heat transfer } \\
\text { coefficient of each layer } / \mathrm{W} / \mathrm{m}^{2 \circ} \mathrm{C}\end{array}$ & $\begin{array}{l}\text { Cold load of } \\
\text { each layer } / \mathrm{W}\end{array}$ & $\begin{array}{c}\text { Total } \\
/ \mathrm{W}\end{array}$ \\
\hline Roof & 1 & 36.6 & 3 & 2496 & \multirow{10}{*}{17028} \\
\hline 8 & 32.8 & 34.0 & 3.12 & 387 & \\
\hline 7 & 30.1 & 32.3 & 4.45 & 1052 & \\
\hline 6 & 27.0 & 30.4 & 4.62 & 1719 & \\
\hline 5 & 26.3 & 29.9 & 4.96 & 1929 & \\
\hline 4 & 26.3 & 29.8 & 4.92 & 1865 & \\
\hline 3 & 26.4 & 29.7 & 4.8 & 1751 & \\
\hline 2 & 26.1 & 29.5 & 4.82 & 1783 & \\
\hline 1 & 26.7 & 29.8 & 4.65 & 1559 & \\
\hline Floor & 1 & 30.3 & 2.33 & 2486 & \\
\hline
\end{tabular}

The cooling load calculation results for each floor was shown in Table 5. The total convection heat transfer between the ceiling and the 8th floor, the floor and the first layer reached $30 \%$ of the total heat transfer. In the remaining $70 \%$, the cooling load of the nozzle air supply layer was the largest Based on the model, the cooling load at this time was $17028 \mathrm{~W}$, and the cooling capacity of the air conditioner that shown in Table 2 was $19422 \mathrm{~W}$. The difference was about $14 \%$. Considering the loss of air duct air conditioning system and the leakage of air in experimental tests, the relative error was basically reasonable. It can be considered that the model can be used to solve the stratified air-conditioning load in a steadystate large-space building.

\subsection{Stratified air conditioning cold load variation condition calculation}

According to the load calculation model described above, the different indoor thermal insulation resistance, outdoor temperature and indoor load rate variation (based on 50 persons) were calculated. Air vertical temperature distribution and stratified air conditioning cooling load were listed in Fig.5, Fig.6, and Fig.7. It can be seen that the change of outdoor temperature has a great influence on the vertical indoor air temperature in lower air conditioning area, followed by the thermal conductivity of enclosure structure. The reason was that the increase of outdoor temperature directly increased the temperature of non-air conditioning area. Convective heat transfer and radiative transfer heat increase greatly from nonair conditioning area to air conditioning area. Meanwhile, the heat teat transfer cause by outdoor temperature also increased to a certain extent. The minimum impact on vertical temperature distribution is indoor load.

The influence of the change of each parameter on the vertical temperature distribution conforms to the actual law, and the accuracy of the model calculation was verified on the other hand.

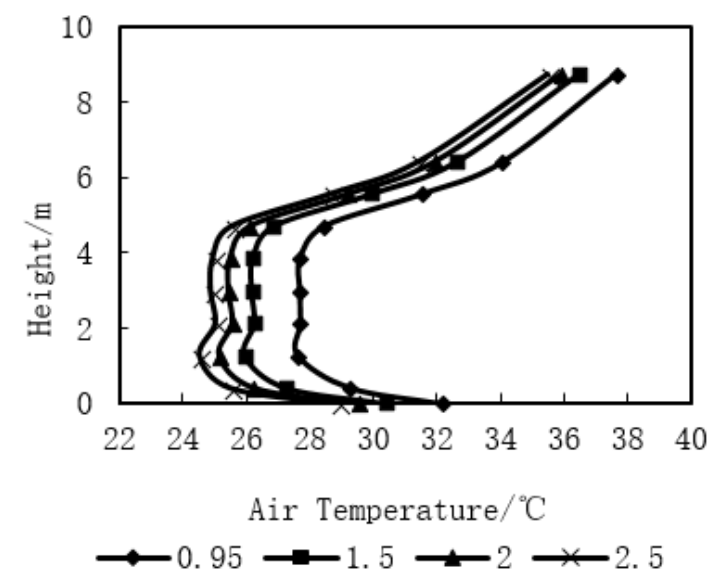

Figure 5. Vertical temperature under different thermal Conductivity $\left(/ \mathrm{m}^{2} \mathrm{k} /{ }^{\circ} \mathrm{C}\right)$ 


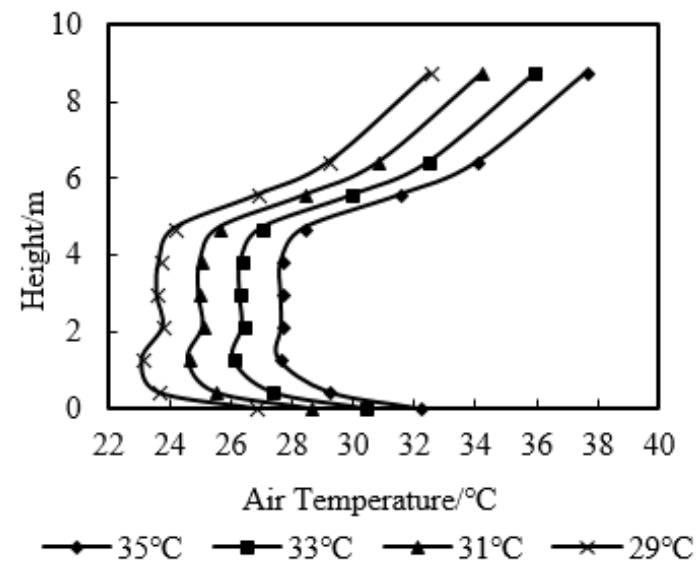

Figure 6. Vertical temperature under different outdoor temperature

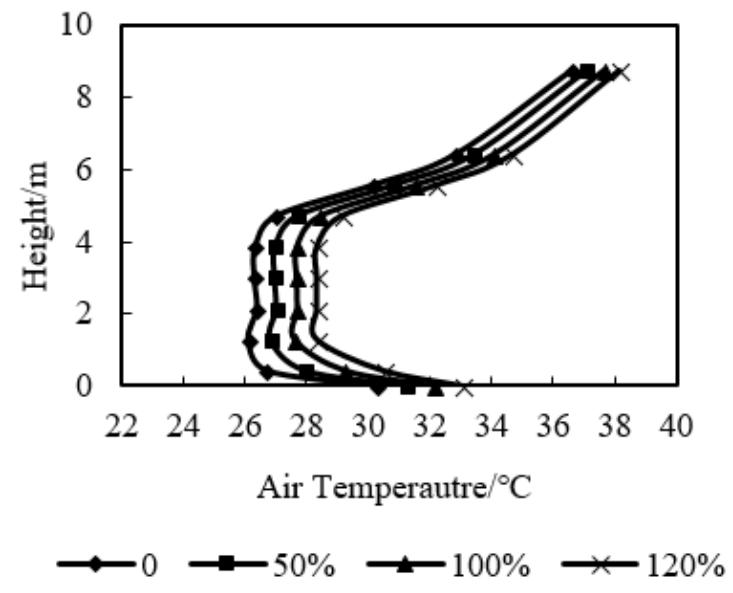

Figure 7. Vertical temperature under different indoor load

\section{CONCLUSION}

This paper proposed a method for calculating stratified airconditioning loads based on large-space buildings, taking into account the subdivision of indoor air temperature in the vertical direction. Through the experimental test of summer large-space buildings, the analytical solution of stratified airconditioning load was compared. The relative error between the air-conditioning cooling capacity calculated by the model and actual load is $14 \%$. The model provided ideas and directions for the calculation of stratified air-conditioning loads in large-space buildings, and had certain practical significance for the early stage of air-conditioning design for large space buildings. In the follow-up study, an unsteady model can be established to take into account the non-steady state factors such as the heat storage of the envelope structure and indoor lighting. The change in the stratified airconditioning load can be analyzed more accurately.

\section{REFERENCES}

[1] Lu YQ. (2008). Practical heating and air conditioning design manual. Beijing: China Architecture \& Building Press 1717-1723.
[2] Nishioka T, Ohtaka K, Hashimoto N, Onojima H. (2000). Measurement and evaluation of the indoor thermal environment in a large domed stadium. Energy Build 32(2): 217-223. https://doi.org/10.1016/S03787788(00)00048-7

[3] Yang GR, Ye DF. (2008). Comparative analysis of calculation methods of cooling load on floor air supply system. HVAC 38(4): 62-66. https://doi.org/10.3969/j.issn.1002-8501.2008.04.014

[4] Zhao K, Liu XH, Jiang Y. (2015). Cooling capacity prediction of radiant floors in large spaces of an airport. Solar Energy 113(2015): 221-235. https://doi.org/10.1016/j.rser.2015.11.028

[5] Chen QY, Glicksman L. (2003). System performance evaluation and design guideline for displacement ventilation. Atalantic: ASHRAE Inc.

[6] Dong K, Cao XM, Hu W, Gao NP. (2011). Study on flow field, temperature field and load characteristics in floor ventilation room. Building Science (12): 87-90. https://doi.org/10.3969/j.issn.1002-8528.2011.12.018

[7] Rahmati B, Heidarian A, Jadidi AM. (2018). Investigation in performance of a hybrid under-floor air distribution with improved desk displacement ventilation system in a small office. Applied Thermal Engineering 2018(138): 861-872. https://doi.org/10.1016/j.applthermaleng.2018.03.015

[8] Ni B. (2000). Experimental study on displacement ventilation. HVAC 30(5): 2-4. https://doi.org/10.3969/j.issn.1002-8501.2000.05.002

[9] Asfour OS, Gadi MB. (2007). A comparison between CFD and Network models for predicting wind-driven ventilation in buildings. Building and Environment 42(12): 4079-4085. https://doi.org/10.1016/j.buildenv.2006.11.021

[10] Wang LZ, Chen QY. (2008). Evaluation of some assumptions used in multizone airflow network models. Building and Environment 43(10): 1671-1677. https://doi.org/10.1016/j.buildenv.2007.10.010

[11] Abadie MO, Camargo MMD, Mendonç KC, Blondeau P. (2012). Improving the prediction of zonal modeling for forced convection airflows in rooms. Building and Environment 48(1): 173-182. https://doi.org/10.1016/j.buildenv.2011.09.006

[12] Togari S, Arai Y, Miura K. (1993). A Simplified model for predicting vertical temperature distribution in a large space. ASHRAE Transactions 99(1): 84-90.

[13] Yu YL, Yang Y, Xie ZY, A new inflow turbulence generator for large eddy simulation evaluation of wind effects on a standard high-rise building. Building and Environment 138: 300-313. https://doi.org/10.1016/j.buildenv.2018.03.059

[14] Wang Y, Wong KKL, Du HM, Jing Q, Tu J. (2014). Design configuration for a higher efficiency air conditioning system inlarge space building. Energy and Buildings 72(2): 167-176. https://doi.org/10.1016/j.enbuild.2013.12.041

[15] Cheng YD, Niu JL, Gao NP. (2012). Stratified air distribution systems in a large lecture theatre: A numerical method to optimize thermal comfort and maximize energy saving. Energy and Buildings (55): 515-525. https://doi.org/10.1016/j.enbuild.2012.09.021 